\title{
Women School Leaders: Entrepreneurs in Low Fee Private Schools in Three West African Nations
}

\author{
Paula A. Cordeiro ${ }^{1 *}$ and Corinne Brion ${ }^{2}$ \\ ${ }^{1}$ Department of Leadership Studies, University of San Diego, San Diego, CA, United States, ${ }^{2}$ SOLES Global Center, \\ University of San Diego, San Diego CA, United States
}

This study explores the opportunities and challenges of women who own low-fee private schools in three West African nations. With the implementation of the Millennium Development Goals (MDGs) in 2000 and the Sustainable Development Goals in 2016, it has become obvious to policymakers that school leadership needs to be a policy priority around the world. Increased school autonomy and a greater focus on schooling and school results have made it essential to understand and support the role of school leaders. Few countries however have strong and systematic initiatives to professionalize

OPEN ACCESS

Edited by:

Kay Fuller,

University of Nottingham,

United Kingdom

Reviewed by:

Marsha E. Modeste,

Pennsylvania State University,

United States

Ken Kempner,

Southern Oregon University,

United States

${ }^{*}$ Correspondence:

Paula A. Cordeiro

cordeiro@sandiego.edu

Specialty section: This article was submitted to Leadership in Education, a section of the journal

Frontiers in Education

Received: 18 September 2017 Accepted: 13 December 2017

Published: 12 January 2018

Citation:

Cordeiro PA and Brion C (2018) Women School Leaders: Entrepreneurs in Low Fee Private Schools in Three West African Nations.

Front. Educ. 2:67. doi: 10.3389/feduc.2017.00067 school leadership and to nurture and support current school leaders. This becomes even more complex for governments given the rise of private schooling in low and middleincome countries worldwide; thus, it is crucial for governments to understand the importance of leadership at the school level and how to nurture and professionalize it. In this study, the authors examine the roles of women school leaders in Burkina Faso, Ghana, and Liberia within the context of MDG 3: promote gender equality and empower women. Because of the many challenges in the public sector in education in low and middle-income countries, the private sector has responded by creating thousands of small businesses. Since a large and growing number of women are leading these private schools, this study presents the findings on the nature of the leadership of these women entrepreneurs. Fourteen school proprietors participated in face-to face interviews about their reasons for founding a school as well as the supports and challenges they face. Findings discuss the limited professional learning opportunities for school leaders in these nations. The study describes the school leaders' desires to help build their nations, and the unique cultural and contextual factors in each country.

\footnotetext{
Keywords: low-fee private schools, school leadership, women entrepreneurs, private schools, sub-Saharan African education, West-African education, education in Ghana, Burkina Faso, and Liberia
}

Wisdom is like a baobab tree; no one individual can embrace it.

-Akan Proverb

\section{INTRODUCTION}

The year 2000 marked the beginning of the implementation of the UN's Millennium Development Goals (MDGs). For the first time in world history, eight goals, ranging from universal primary education to ensuring environmental sustainability, were identified with a target that they be met by 2015. Although that did not occur, the fact that 198 of the world's nations and leading development 
institutions set goals and began to gather baseline data in order to measure progress is, in itself, a major achievement. Setting the MDGs was historic and "galvanized unprecedented efforts to meet the needs of the world's poorest." ${ }^{\text {"1 }}$

This article describes the results of a study conducted in three West African nations exploring MDG goal 3: promote gender equality and empower women. A few of the targets of this goal included: achieving equality in primary education between girls and boys, increasing the political participation of women, reducing violence against women, and expanding work opportunities for women. The authors focused on the target of expanding opportunities for women who work in education as school leaders.

\section{BACKGROUND}

In order to understand the expanding school leadership role of women in some of the least developed nations of the world, we have organized the background literature into six sections. We begin by providing a brief update on the status of the MDGs and the newly developed Sustainable Development Goals (SDGs), which started in 2016. This is followed by a brief summary of the literature on women school leaders with a particular focus on women in developing nations. The next section includes a summary of the role of private schools for the poor and how financing them has changed in the past two decades. Then, we briefly explain the context of the three developing countries included in this study. This is followed by information about operating businesses within these contexts. In the final section, we briefly summarize educational progress in all three nations.

\section{The MDGs and SDGs}

When the MDGs were enacted in 2000, Goal 2-achieving universal primary education-was targeted-“to ensure that, by 2015, children everywhere, boys and girls alike, will be able to complete a full course of primary schooling" http://www.un.org/ millenniumgoals/education.shtml (retrieved 9/5/17).

Overall, incredible progress was made. For example, enrollment in primary schools in developing regions reached $91 \%$ in 2015 , up from $83 \%$ in 2000 . Among youth aged 15-24, the literacy rate improved globally from 83 to $91 \%$ between 1990 and 2015, and the gap between women and men narrowed. However, huge challenges remained with children in the poorest households being four times as likely to be out of school as those in the richest households and "In countries affected by conflict, the proportion of out-of-school children increased from $30 \%$ in 1999 to $36 \%$ in 2012" (Millennium Development Goals, 2015, p. 7).

Governments in developing nations faced huge challenges when they agreed to the MDGs. There were far too few publicschool facilities necessary to accommodate the numbers of children who needed to be enrolled and the education ministries and district offices were severely understaffed. Additionally, most developing countries had few teacher training colleges and those that existed did not have the capacity, or the resources, to prepare the huge numbers of teachers needed to ensure that

${ }^{1}$ http://www.un.org/millenniumgoals/ (retrieved 9/2/17). all of a country's children attend school. With the advent of the MDGs, millions of children started primary schools and public schools could not accommodate them. Thus, in the 1990s, tens of thousands of private schools began to appear in the majority of developing nations (Tooley, 2009). In the early years, most ministries of education were not aware of the existence of these schools. With data collection required by the enactment of the MDGs, nations such as India, Nigeria, and Ghana, among many others, recognized that private schools did indeed exist, and they needed to be registered with the ministry of education. Thus, most developing countries now have requirements for opening and operating a private school. It should also be noted that the vast majority of these schools are for-profit rather than not-for-profit. A key reason is because developing nations do not have the tax laws and incentives which foster donations that countries such as the US have and thus, schools are opened as businesses with the school owner or proprietor having to fund the operations of the school.

In 2016, the MDGs transitioned to the SDGs, which will be in existence until 2030. There is a total of 17 goals with dozens of targets for each goal. These goals build on the original eight MDGs. Two are of specific relevance to this study: Goal 4: Ensure inclusive and equitable quality education and promote lifelong learning opportunities for all; and Goal 5: Achieve gender equity and empower all women and girls. One target for this goal is to: Ensure women's full and effective participation and equal opportunities for leadership at all levels of decision-making in political, economic and public life.

\section{School Leadership in the Least Developed Nations}

Much has been written about the important role of school leaders in Western nations (e.g., Leithwood, Sergiovanni, DarlingHammond, Cordeiro, and Cunningham); there is, however, little empirical research about the work of school leaders in developing nations. The little research that does exist (Walker and Dimmock, 2002; Lumby et al., 2009; Schleicher, 2012) has been conducted primarily in the past 5-10 years, tends to be more descriptive than empirical and addresses middle-income countries rather than the least-developed countries (LDCs). ${ }^{2}$ There is even less research on school leaders in Sub-Saharan Africa, with some notable exceptions (e.g., Oduro and MacBeath, 2003; Bush and Oduro, 2006; MacBeath et al., 2010). Similarly, there is little research on leaders of private Faith-Inspired Schools (FSIs), since most studies explore leadership in government (public) schools. One important and notable exception is the 2014 special issue of Faith and International Affairs in which guest editor and World Bank adviser Quentin Wodon assembled seven research-based articles focusing on FISs in sub-Saharan Africa. Wodon maintains that "...there is a renewed and growing recognition that

\footnotetext{
${ }^{2}$ As of February 16, 2016, the UN General Assembly designated forty-eight nations as Least Developed Countries (LDCs). The majority of the LDCs are in Africa and Asia. There are three criteria: low income, human resource weakness (e.g., health education literacy) and economic vulnerability. (The Least Developed Countries report 2016. United Nations).
} 
FSIs have an important role to play in the efforts undertaken by Ghana [and other developing nations] to achieve the Millennium Development Goals" p. 2. Finally, with few exceptions (e.g., Oplatka, 2006, 2009; Zhong and Ehrich, 2010; Arar, 2014) research on women school leaders in public or private schools in LDCs has been minimal.

Because the women included in this study have "education businesses" we reviewed the literature on women in business in general as well as women in school leadership in LDCs. The majority of studies in education in low-income countries described the work of teachers, and at times, principals of public schools. Private schools are unique; especially private schools that are for-profit. For example, unlike nonprofit schools in Western nations these schools are not required to have a board of directors nor in most cases do they receive any type of government funding.

Small business entrepreneurs continued to be key to economic and educational development in the majority of developing nations because unemployment is so high and the governments, in most cases, provide few support structures. This is analogous to small businesses around the world, such as those at thousands of local markets that provide employment for millions, if not hundreds of millions, of people. Thus, better understanding the exponential growth of small businesses can contribute to our understanding of educational and economic development in the LDCs.

\section{Private Schools in Developing Nations}

In their seminal research about private schooling in developing nations, Tooley and Dixon (2007) discovered that many countries had large numbers of low-fee private schools (LFPSs). ${ }^{3}$ They found that in many cases ministries of education did not recognize these schools and often government offices denied their existence. However, the reality is quite different since thousands of LFPSs exist and subsequent to Tooley's original research, other scholars (Cordeiro and Llover, 2012; Kwan, 2012; Spencer et al., 2012; Srivastava, 2013; Day Ashley et al., 2014) and international nongovernmental organizations (e.g., IDP Rising, Opportunity International, Edify) have been working to research, expand and/or strengthen the LFPS sector particularly through micro-lending and small business loans. Currently, countries, such as India, Peru, Guatemala, Colombia, Dominican Republic (DR), Ghana, Burkina Faso, Nigeria, Liberia, and Rwanda among others, have large numbers of LFPSs and these independent schools are rapidly increasing throughout the world.

One way to categorize LFPSs in developing nations is by the reasons for which they were created. Similar to the history of private schooling in the US, a large number of LFPSs are church affiliated (Wodon, 2014). Often the pastor and his wife run the school and parishioners' children are the target audience. There are secular private schools in addition to public and religious schools. The emergence of large numbers of private schools,

${ }^{3}$ The literature uses the terms Affordable Private Schools (APSs), Low-Cost Private schools (LCPSs), and Low Fee Private Schools (LFPSs) interchangeably. In this paper, we will use the more generally accepted term of Low-Fee Private Schools. whether faith-based or secular, is not surprising given that many public-school systems in undeveloped nations did not have the resources to serve thousands of children who had not previously attended school who would now attend schools in order to meet the MDGs (Cordeiro and Cunningham, 2012).

As these proprietary schools expand, their need for additional capital has emerged. Commercial banks have been unwilling or unable to provide microloans or small business loans to the sector; thus, the microlending industry has spread to educationrelated businesses.

\section{The Context of Three West African Nations: Burkina Faso, Ghana, and Liberia}

For this study, we selected three West African nations: Burkina Faso, Liberia, and Ghana. Since one of our NGO consulting clients, has operations in these nations, we had easy access to school proprietors in all three countries.

Burkina Faso. As noted by Mendonsa (2002) before attaining autonomy, Burkina Faso was called French Upper Volta and in 1960 attained full independence from France. It is slightly larger than Colorado, which is the eighth largest state in the US; however, Burkina has nearly four times the number of people with nearly 19 million inhabitants. ${ }^{4}$

The people of Burkina Faso refer to themselves as Burkinabe. Burkina is a multilingual country with the Mossi language spoken by about $40 \%$ of the population. In Mossi, Burkina Faso means "land of the upright (honest) people." Although similar in size to Colorado, its population of approximately 18 million is nearly four times as large. About $60 \%$ of the population is Sunni Muslim and roughly $23 \%$ are Christian. The World Bank has labeled Burkina Faso as a low-income country. Since the $1980 \mathrm{~s}$ there have been several coup d'états and, although overall a peaceful nation, it remains politically unstable (Dowden, 2008; Bado, 2016) and is frequently the target of ISIS-related militants (US Government alert retrieved 9/4/17).

Ghana. With a population of 26 million people, Ghana is located on West Africa's Gulf of Guinea. Francophone countries, including Burkina Faso to the North, surround it; however, English is one of the main languages of Ghana and thus is the language of instruction in Ghanaian schools. Ghana was formed when the British colony of the Gold Coast and Togoland Trust Territory merged. It is a little smaller than the state of Oregon in size but it is closer in population to the state of Texas. In 1957 Ghana became the first Sub-Saharan country in colonial Africa to gain its independence (Mendonsa, 2002).

Liberia. Bordering Sierra Leone on the west, with Guinea to the north and the Ivory Coast to the east, Liberia is similar in size and in population ( 5 million) to the state of Alabama. In 1847 the American Colonization Society founded Liberia. Freed American slaves relocated to Liberia throughout the $1800 \mathrm{~s}$ and governed the nation until recently (Mendonsa, 2002). After a succession of coups in the second half of the 20th century, in the 1980 s Liberia experienced two brutal Civil Wars lasting

${ }^{4}$ www.worldometers.info/world-population/burkina-faso-population (retrieved 9/5/17) 
over 14 years. In 2014 Liberia suffered the devastating effects of the Ebola virus and more recently there has been catastrophic flooding. ${ }^{5}$ Although Liberia is currently a stable democracy, the country is facing severe economic, health, and education challenges and the country's infrastructure is particularly weak.

\section{Operating Schools as Businesses in the Three Nations}

There are four indices that have implications for the proprietors of private schools and particularly for women who own schools in developing nations. The Human Development Index (HDI) is a summary measure of the average achievement in key dimensions of human development such as a long and healthy life, being knowledgeable and having an adequate standard of living. On the $2016 \mathrm{HDI}$, all three countries ranked particularly low. Out of 188 countries, Ghana ranked 139, Liberia 177, and Burkina Faso 185. The Gender Inequality Index http://hdr.undp. org/en within the HDI measures gender inequalities in three key aspects of human development: reproductive health, empowerment and economic status. The Index plays an important role in highlighting areas in need of policy intervention. In the 2015 data, Ghana ranked 131, Liberia 150, and Burkina Faso 146 out of 188 countries. Although great strides have been made for women in many LDCs since 2000, they have not yet achieved gender equity. Too often, women (and girls) are discriminated against in health, education, political representation, labor market, etc., with negative repercussions for development of their capabilities, their freedom of choice and for their children. This remains true in the three countries discussed included in this study.

A third index with implications for women school entrepreneurs measures corruption. According to Transparency International ${ }^{6}$ of the 176 countries ranked on corruption in 2016, Ghana ranked 70th, Burkina Faso 72nd, and Liberia was 90th.

Finally, the World Bank annually publishes rankings for the ease in which business can be conducted in a nation. Factors such as starting a business, getting electricity, obtaining credit, and paying taxes, among others, comprise the "Ease of Doing Business" ranking. In 2016 of the 190 countries included in the index, Ghana ranked 108, Burkina Faso 146, and Liberia 174. Thus, starting and operating a business in all three countries is particularly daunting. ${ }^{7}$

\section{Educational Progress in Burkina Faso, Ghana, and Liberia}

With regard to educational progress, Ghana is the only country of the three that participated in the Trends in International Mathematics and Science Study (TIMSS). In 2011, Ghanaian 8th graders took this mathematics achievement test, and of the 43 participating countries, Ghanaian students scored the

\footnotetext{
${ }^{5}$ http://www.africanews.com/2016/07/02/heavy-flooding-in-liberia-paralyzestransport-in-the-capital/.

${ }^{6} \mathrm{https} / /$ www.transparency.org/news/feature/corruption_perceptions_index_ 2016\#table.

${ }^{7}$ http://www.doingbusiness.org/.
}

lowest. Ghana did not participate in the 2015 test, nor do any of these nations participate in other international assessments (e.g., PISA). Suffice to say, for all three West African nations, inadequate schools and supplies, as well as a lack of qualified teachers hamper the education sector. All three countries have made progress on increasing the number of children completing primary school (especially in Ghana and Burkina Faso) and in gender equity in school, however, progress is uneven and poverty remains a major barrier to education.

According to the most recent data (2014) adult literacy rates are particular low in each of the countries with the average for males and females as follows: Burkina Faso: 36\%, Liberia 47.6\%, and Ghana $76.6 \%$. It is important to note that these averages understate illiteracy for females, who in all three countries have higher illiteracy rates than males. For example, Burkina Faso has one of the lowest literacy rates in the world, ranking 157 out of 160 countries. The literacy rate for males is at $43 \%$, while for females it is only $29.3 \%$ https://www.cia.gov/library/ publications/the-world-factbook/geos/print_uv.html (retrieved 9/5/17). In 2015 during data collection for this study, Ghana, Liberia and Burkina were categorized by the United Nations within the group of "least developed countries." These are nations that exhibit the lowest indicators of socioeconomic development. In February 2016, just after data collection was completed, Ghana was removed from this list and is now referred to as lower middle-income country http://www.worldbank.org/ en/country/ghana/overview (retrieved 9/5/17).

Given that there is exponential growth in the for-profit private school sector and that education is intimately tied to economic development, better understanding the challenges faced by school proprietors can shed light on school improvement. Additionally, with the SDGs focusing on improving access to and quality of schools as well as ensuring women opportunities and equity in work, the authors decided to examine the challenges and opportunities for women school entrepreneurs in these developing nations.

\section{THE RESEARCH STUDY}

The researchers are consultants to an international nongovernmental organization, Edify, for whom we have created training materials, designed and implemented research projects and conducted independent impact evaluations. Edify is a faithbased organization providing training to personnel of the schools they support in the areas of leadership, Christian transformation, technology, literacy and financial sustainability. They have headquarters in the US and ten regional offices in Africa, Central/ South America and India. We collected data for this project separately from our work with the NGO because of our keen interest in these women entrepreneurs. We are indebted to Edify for affording us the opportunity to gain access to these women who are recipients of their services.

\section{Research Questions}

The purpose of this study is to present the findings on the nature of the leadership of women school proprietors in three West African nations who founded and lead LFPSs and to investigate 
the issues they experience given the context of education in their nations. Two research questions guided this investigation: (1) How do women school proprietors in LFPSs in Burkina Faso, Ghana and Liberia view themselves and their roles? (2) What contextual differences, if any, exist for these women in their roles as proprietors?

\section{Method and Data Sources}

In 2013, while conducting an initial investigation to assist the NGO in developing an education strategy, one of the researchers interviewed 16 proprietors of LFPSs in the DR and Ghana. Of the six interviews in the DR, four were with women, and of the 10 in Ghana, two participants were women. A maximum variation sampling approach was followed, since the purpose of these original interviews was to learn about variations from a wide range of schools (primary, secondary, vocational, urban, rural, etc.).

Interviews lasted approximately $1 \mathrm{~h}$ and the interview protocol included several questions which ethnographic researcher and anthropologist James Spradley (1979) called "grand tour" questions. They included questions such as: "Tell me about how, and why, you founded this school? What supports helped you to develop the school and what were some of the barriers?" Stories about the founding of the schools, which in many cases began as childcare centers, emerged from the eight women as well as a few of the men. Most of the male proprietors who told their stories discussed how their wives had been taking care of children in their home and how they (the husband) saw this as an opportunity to start a business. Although not the original reason for the interviews, over time the researchers continued to hear this story when working in other LDCs.

Also used as background for the designing of this study was a set of interviews conducted in 2014 as a follow-up to a randomized control trial (RCT) designed and implemented by one of the authors (Cordeiro and Spencer, 2015). The RCT took place in summer 2013 in Ghana and part of the follow up, which included in-depth interviews with school proprietors or head teachers/principals who had experienced the treatment for the RCT, occurred in January 2014. We conducted a total of 18 interviews, with seven of the proprietors or head teachers being female. Once again, although women school leaders were not the focus of the RCT, differences in the way women answered the researchers' questions on the follow-up qualitative section of the study, compared to men, became evident. For example, many women described their "passion" and "calling" to lead a school, while male participants talked far more about the financial and business aspects of their work. Thus, because of the differences in how women spoke about their work in this way, we decided to conduct a qualitative study exploring the rationale behind why women started schools as a business, how they viewed their roles, what dreams and goals they had for the future of their schools, and if there were differences among countries. We used the data from 15 interviews with female proprietors from the two earlier investigations in order to develop the research questions and interview protocols for this study.

\section{Participants, Interview Protocol, and Coding}

For this qualitative study, there were two forms of data collection: in-depth interviews and document analysis. A total of 14 interviews took place in three countries. Four interviews were held in Burkina Faso, six in Ghana and four in Liberia. Interviews occurred between January 2014 and February 2016. They lasted from $90 \mathrm{~min}$ to $2 \mathrm{~h}$, with most interviews taking place in the school proprietors' offices. All interviews were digitally recorded and fully transcribed. The transcripts from Ghana and Liberia were in English. Since one of the researchers speaks French, the transcripts from Burkina Faso s include More (Burkina Faso), Ga, Fanti, and Twi (Ghana) and in Liberia, 30 languages are spoken with none of them representing a distinctive majority.

A combination of convenience sampling and maximum variation sampling was employed. Since the client NGO has schools located throughout all three of the countries and the authors had the opportunity to interact with dozens of school proprietors, we first identified female proprietors who were (1) geographically located in the vicinity of our work during a particular country visit; (2) had operated their schools for at least 5 years; and (3) spoke either English or French well enough for us to conduct the interview. We also sought to include schools that had variations as in the grade levels offered and the number of students in the school.

We used the in-depth research interviews as conversations (Kvale and Brinkman, 2009). The f14 transcripts were first coded by initial coding themes followed by selective or focused coding (Charmaz, 2014). The Interview Protocol consisted of basic background information about the school followed by five grand tour questions and several probing questions and prompts. Samples of questions included: "Tell me about how your school was founded. How did you become the proprietor of this school and why? Have you/do you have other leadership positions? What's it like to be a woman school proprietor in (name of country)?"

A second source of data collection included a review of documents, including school newsletters, handbooks, letters to parents, etc. In one case, a female school proprietor who was not comfortable with her level of English typed her story of the founding of the school for the researchers in advance of the interview.

This study was carried out in accordance with the recommendations of the University of San Diego's Institutional Review Board (IRB). It was approved in December 2013 by the IRB.

\section{Limitations}

It is important to note that this study has numerous limitations. None of the researchers speak the participants' native languages and often in the transcripts the researchers may have missed the nuances of what these women were explaining. Although we have spent a considerable amount of time working and living in these nations, both the researchers are "oburonis." In many cases there was considerable noise in the background since most interviews took place in schools with open windows

\footnotetext{
8"Obouroni" is the Akan (Twi language) word for a Western white foreigner.
} 
and doors. As a result, transcribing the recordings proved challenging and, in some cases, content many have been missed or misconstrued. Since the local NGO staff usually accompanied us to the interviews and were trusted by the participants, they were often in the room during the interviews. In some ways, this was helpful since we were able to use them for member checking (Creswell, 1998) to see if what we had understood was accurate. Conversely, there may have been some hesitancy in responses by participants since another person was in the room. Finally, these findings are delimited to only three countries in West Africa, a region comprised of 16 nations.

\section{FINDINGS}

The findings are divided into five sections. We begin by discussing the reasons that participants founded their schools. The next two sections describe the general supports, and the networking supports identified by participants. The final two sections present the financial and gender challenges faced by these women entrepreneurs.

\section{Motivations for Founding a School}

There were many commonalities among the 14 proprietors. Since all of these women are mothers having two to nine children, they often spoke about needing to educate their own children as being the impetus for starting what began as a daycare center with primary grades added later. They repeatedly discussed how they enjoyed this work and how their friends, and other parents, asked them why they did not add a kindergarten and then a primary and eventually a junior high school. One proprietor's comment is typical of most of the participants, "[I] started with just the crèche and nursery. ${ }^{9}$ So, then as time went by we added the kindergarten to it...I started in my living room... and now we have JHS $3 . "{ }^{\prime \prime}$ So, the typical school began as a daycare center and then as one commented, "I build a class [room] each year."

Although the proprietors in Liberia also tended to start their schools as daycare centers, they talked about seeing displaced children in the streets after the 14-year civil war as their motivators to start a school. One commented, "We founded the school because there were a lot of displaced students ... who were not going to school." Another Liberian proprietor stated, "I was a market woman...selling women's clothing. I saw little children, from five to seven years [old] and I would call them and I would ask, "Why are you not in school?" And they would just stand there and they would not answer....so I have the passion for the little ones ... so I started a school." Another commented, "After the war...I saw children loitering around, there was nowhere to go to school... I started in the garden... of my house and so I decided to fix it up for a school...we started with pre-nursery and nursery."

${ }^{9}$ Because so many private schools began as daycare centers, many schools in these and other developing nations frequently start with children as young as one year old and typically go through junior high school or even high school.

${ }^{10} \mathrm{JHS} 3$ is the final year of junior high school in Ghana. The Ghanaian educational system has 6 years of primary, three years of Junior Secondary School and three years of Senior Secondary School.

\section{Support}

All participants had certain motivations and support in common for undertaking this type of work. Several talked about the important and supportive role of family members. Another stated, "It hasn't been easy. I had to pull in my husband... He has been very helpful...It was my husband who gave me the money to buy those things." Another proprietor told a story of how her brother who is a welder, "crafted 45 chairs for the school" with her only needing to cover the costs of the materials.

Other proprietors discussed support they received from friends and/or community members. When discussing the assistance she received in the early years of her school, one Liberian proprietor commented, "A senior citizen in our church ... gave us $\$ 3,000$ (US)." Other proprietors talked about the importance of their friends with one commenting, "I have friends who run other schools...we meet and talk about challenges and things like that...it's been very helpful." However, with regard to family members, others stated that their husbands, extended family and children were at times either ambivalent or not supportive of them starting a school. One commented, "At first it was not easy ... I had to fight alone."

All the women in this study described how they loved working with children and their passion for children being one of their biggest motivators to start a school. One comment is typical of the sentiments of the participants, "It is my love for children that pushed me to open a school."

The majority of women proprietors from Burkina Faso and Liberia commented about how they were motivated to make their nation a better place; in fact, they considered themselves nation builders. One proprietor stated, "I really see that ... it is all about education...the children are insurance for the future... of the country." Another example that is illustrative of several comments, is what one proprietor said about her role as a school leader having a much larger impact, "I like being able to do something for the development of my country."

Religious beliefs were also a strong motivation for these women. Their belief in God was repeatedly mentioned as one of their main supports. One proprietor described how she has three friends from her church, "We have our group [of women], we meet at individual's homes and pray." Another stated how she and her friends "...met and prayed together and decided that they should open a school." In order to open the school, they sought support from their church and then annually taxed themselves to provide money for the school. Then she added, "We got confirmation from the Lord that it [the school] should be all girls." The mentioning of God as a key source of strength by the majority of the participants is not surprising given that all of the schools in this study are Christian schools. Even though many of the schools serve children who are of other faiths (e.g., Muslim) or of no faith, they clearly find their belief in God to be a major support and inspiration for them.

\section{Networking Supports}

Several women from each country talked about professional organizations and NGOs that had either supported them or offered them opportunities to network and develop their 
leadership skills. In Ghana, there is a professional association for private schools called the Ghanaian National Association of Private Schools (GNAPS), which also has local district affiliates. Several participants made reference to involvement with GNAPS and one proprietor in this study serves on the executive committee of a regional affiliate. Another professional association is the Ghanaian Early Childhood Association which deals with schools targeting children birth to six. One proprietor stated, "After being in the association for five years...I was elected as their regional president .... we organized workshops, seminars, and courses for daycare attendants." In Burkina Faso, one proprietor mentioned her involvement with the Independent Schools Association; however, this was the only reference to a professional association network. Other proprietors referred to trainings offered by Edify, MicroAid (the micro-lender in Burkina Faso) and the Liberian micro-lender, the Foundation for Women. Also mentioned were financial trainings offered by two banks in Ghana: Opportunity International Bank and Barclay's Bank.

Two proprietors in Liberia discussed the importance of being invited to participate in Goldman Sachs' 10,000 Women Strong program, which was created for women in 56 countries in any sector of business. Based on a growing body of research to support the economic opportunity of investing in women, Goldman Sachs launched this program in 2008. The program provides women with business management education, mentoring, and networking and access to capital. ${ }^{11}$ Liberia is the only country in this study included in Goldman Sach's program and it is now over.

Finally, in Ghana, a grant from the World Bank created a now defunct program: the Ghanaian Association of Women Entrepreneurs. One women proprietor described how wonderful it was to have an opportunity to go to the World Bank in the US, and with her group, make a pitch for funding a project.

No mention was made by any of the participants about the government, or government offices being supportive to them in their work. In most cases, if a school was visited at all by a government official, it was only for the initial inspection when the school was registered.

Lastly, several Ghanaian women described how they had either returned to school many years later or were currently taking classes themselves and found this to be most helpful. One proprietor commented that in order to get a certificate in early childhood education she, "... went back to the University of Education in Winneba." Others talked about "sandwich" courses for themselves or their teachers. Although not as plentiful, at times relevant, or convenient as they would like, the proprietors in Ghana do have higher education resources and professional associations available to them for their learning and their teachers' professional development.

\section{Challenges: "Funding Was Almost Inaccessible."}

All 14 female proprietors talked about experiencing considerable hardship as they founded and expanded their schools. Referring

\footnotetext{
${ }^{11}$ http://www.goldmansachs.com/citizenship/10000women/.
}

to being a businesswoman and leading a school one participant captured the sentiment of the others by stating, "It really takes a lot of courage." A challenge that all proprietors discussed, which is not unique to women proprietors, revolved around finances. Since these schools serve low-income families, there are ongoing concerns about families not being able to pay tuition. One proprietor commented, "We serve families that sell in the market... they don't have regular incomes." Another said, "Many parents are single parents... a woman with several children...she might have two jobs...they can't pay on time." Another commented that when parents cannot pay, "I let the child finish the semester... they can return the next semester if they pay in advance for that term...we don't make them pay when they didn't have work." Another reason given by the proprietors for parents not being able to pay tuition in Liberia was due, as one proprietor stated, to the "Ebola, of course."

One woman, who was divorced with five children and had no support from her ex-husband, commented about how hard it was to run a business and raise five children, "I was suffering for my children [meaning they had only one parent]. It was living day to day...I made batik and sold it in the market... I told myself I had to do something so my children could eat. So, I opened a school...we have many orphans, street children, the less privileged...I sew them free uniforms and feed them for free." She then talked about how crucial microloans were to her expanding the school, which now has 800 children. She also detailed a unique approach to collecting tuition, "Some people decide to pay daily... we sit down and calculate the fees ... whether it [fees] is paid daily, termly, monthly or weekly ...they are paying the same amount."

These women also worried about having enough money from tuition revenue to pay teachers. One comment that is representative of the sentiment of the proprietors was, "It's very difficult to get good teachers, very difficult!" She explained that in addition to trying to provide a good working environment, she tries to offer other benefits to teachers besides salary, "Teachers had to leave the classroom to enroll in education courses. We pay them to take courses... They are out of the classroom; it means we need to get somebody else to come in. But we are still paying [the teachers] a salary." 12

When talking about her school, one Liberian proprietor described how people from her church got together, with one donating land since she had no money. "The children helped with the bricks...everybody worked. We bust rocks." She commented that her school is serving some of the poorest families in Liberia and noted that the employment of most of the parents was as "rock crushers."13

\footnotetext{
${ }^{12}$ In all three countries, there is a shortage of trained teachers. Although there are government requirements for primary teachers to hold a degree, the reality is quite different. The vast majority of private school teachers in the LFPSs in all three countries do not hold a bachelor's degree. Of the three nations, Ghana has the most developed higher education system and there are teacher-training colleges. They have developed "sandwich" courses which are short courses offered between terms so that practicing (mostly unqualified) teachers can participate.

${ }^{13}$ Crushing rocks is one of the only ways for many of the poorest in Liberia to make a living. Piles of rocks can be seen throughout Monrovia and other urban areas along the sides of streets. Usually, a man is sitting on the ground breaking larger
} 
These entrepreneurs struggle with balancing many fiscal challenges. Once they finally find the start-up monies to either buy or rent land, and build a structure or expand their homes to accommodate classrooms and playgrounds, they struggle with trying to support low-income families who have difficulty keeping up with tuition payments. In addition, finding and keeping quality teachers is a huge and ongoing financial challenge. "Sometimes I just can't sleep because I'm so worried about these things," one proprietor lamented.

There are also challenges with land ownership. Either the proprietors did not have the initial money to purchase the land and had great difficulty getting it (e.g., getting a bank loan since they have little or no collateral), and/or at times other people claimed to be owners of the land. The idea of holding title to a property is a fairly recent concept in these nations. In several cases, participants talked about how their fathers or husbands gave or sold them the land. Registering property is difficult in all three countries with it taking months to do so, and petty corruption is also an issue. One proprietor described how she had to provide a dash ${ }^{14}$ to the local official. One proprietor told us a story about how difficult it was to get official ownership of her land and how long the ordeal took. Apologizing for being nearly in tears, she related a harrowing story. After having her fatherin-law help her get the land and having made payment on it, "somebody stole my land" she commented. "We had demarcated the land and put the name of the school up... and he took it. I went back to the man we bought it from and he said I sold the land to you. So, you take charge of it. That strengthened me and so [I] got some money and bought blocks, put it on the land, bought sand and put it on the land, bought stones! So, I just [re] claimed the land! And the police had to get involved... but I had the papers and he didn't...it took three years... to resolve this ...I wasted ...so much of my time."

Another proprietor said, "...there is a problem of [lack of] resources. There is the problem [of getting] land...more hurdles for women proprietors...the acquisition of land."

\section{Gender and Culture Challenges: "Wife Homework"}

Throughout all of the interviews, culture and gender issues emerged either directly or indirectly. Their gendered roles are significant social and cultural challenges for many of the women. Interestingly, several participants strongly believe these roles are what make men and women unique and should be the way they are.

Of the 14 women interviewed, seven were married, two widowed, and four were divorced. As reflected by our sample, divorce, although not common, is more typical in Ghana and Liberia, while in Burkina Faso it is rare for a woman to divorce. Of the eleven women who were either currently married or widowed, four reported that their husbands were supportive from

stones with a hammer. Construction workers and others stop to purchase barrels or truckloads of these broken stones.

${ }^{14} \mathrm{~A}$ dash is West Africa is a small "gift" that one gives in order to do business. In other African nations "chai"-tea, is used while in some French speaking nations such as the Congo un petit sucre-a little sugar is used. the beginning. The remaining seven made strong statements about how difficult it is to be a wife and a school leader because of cultural expectations. In explaining why, she came to the education world later in life, one proprietor stated, "I am a pastor's wife and if his wife is not at hand, women can't approach the pastor... Here in Burkina Faso everyone is suspicious. If a pastor's wife is not at home, another woman cannot go there....so this is what prompted me to stay home and help him in his ministry." Several women talked about having to balance their work and home life since their spouses were not supportive. These women were very aware that they were doing so, and resented it. One proprietor commented, "I could not talk about my day with him...I suffered economically and psychologically...I felt he really abandoned me...He always wants to feel that the woman is property." Later she commented that, "Culturally it is significant to have a husband...because it helps with customers and staff, otherwise people talk and you lose their respect." One woman, commenting as to why Burkina has so few women proprietors stated, "Generally many women do not work [outside the home] ...we do not have the opportunity. Sometimes we feel less valuable than men when they look at us." She later went on to say, "I need to prove to men I can do it alone and not expect them to do something for me." One proprietor, who was a widow, commented about what her husband had been like, “... whatever your level of education, whatever your responsibilities, he is still in charge. I had to forget my responsibilities as a director and a founder. I had to be submissive...I had my chores to do at home. I had my "wife homework." Another commented, "Women have to be educated. They have to value themselves. ...We have not yet reached to the margin of women being empowered without the man."

Another proprietor commented, "It's not easy [being a woman proprietor]. Some of the parents...challenge me and don't want to pay." She stated that she had to get her male principal who would say, "Now... just take it easy...they have to pay," and then the two of them would "... go to confront them."

When talking about the early years of her school one proprietor commented, "My number one challenge was my husband ...He thought I should be there to prepare his food...he'd call, where are you? What are you still doing on campus? ...the first year was horrible." Typically, some married women who had unsupportive husbands when they first opened the schools, found that over time their husbands began to support them. One commented, "He changed his mind about things when he attended the first graduation... he saw the children and myself all giving embraces and I told him, 'thank you for allowing me to be here.' So, he embraced me and told me, "thanks!" And from that time on...he was fine."

Another woman with an unsupportive husband commented that it "wasn't until the third graduation that he started to understand and be supportive." Another said, “...my husband was the number one person who thought I was being too ambitious...he felt threatened...the school was growing in leaps and bounds...I am a school proprietor. I'm an entrepreneur." She later added that they are now divorced.

Other women discussed religion and gender together and several attributed gender differences to the way God made men 
and women. One proprietor stated, "We women, I think God created us in such a way that you have this intuition... and you think about things ...I think we think deeper [than men]." She went further and said that she felt men did not have the same depth of care about others, "We think about the welfare of the children and the welfare of the teachers, how to make the school look good, how to have more children in the school...we are different in our makeup. God made us differently...our makeup is different... we think differently."

One statement interestingly captures the intersection of how the church in her country views women and the role of her gender, "I'm a member of the Women's Group in church. We are called the PVV, that's the Precious Vessels of Virtue, the women's organization."

\section{DISCUSSION}

All the women interviewed for this study were highly motivated to have successful and sustainable schools. Their passion and love of children and the importance of God in their lives were frequently mentioned as their motivations for founding schools. In spite of many obstacles, the majority of the Ghanaian school proprietors returned to school themselves in order to improve their skills; however, it is not surprising that no one in Liberia or Burkina discussed how they were formally expanding their knowledge base on school leadership since the higher education institutions of these countries do not yet have the capacity to meet the lifelong learning needs of their citizens. All the women interviewed saw themselves as leaders and many of them have engaged in formal and informal leadership roles beyond their schools. They recognize the importance of networks; however, for some, especially in Burkina Faso and Liberia, networking and professional development opportunities are limited or nonexistent.

Because of wars, deep poverty and economic and political instability, the women in both Liberia and Burkina Faso were also motivated to make their nation a better place and considered themselves to be playing an important role in building and developing their nations.

Being part of a formal church is connected to the role expectations of women in some societies; however, in none of these churches are women allowed to be pastors and their roles tend to be supportive yet deferential to men. So, although in some cases the women in this study found their churches to be supportive they had little opportunity to nurture or demonstrate their leadership skills except in forming youth groups.

The challenging working contexts of these countries are taxing issues for school proprietors. For example, in all three countries there is limited and/or unreliable access to electricity meaning that schools need other power sources to ensure lighting critical for teaching and student learning. Thus, school proprietors in these nations incur additional expenses and hardships to operate. Other business challenges mentioned by many participants included: the inordinate length of time to start their businesses, dealing with obtaining construction permits, the difficulty of getting access to credit and the lack of contract enforcement, to name but a few. Also, because of the uniqueness of a school as a business, there are other government offices to deal with beyond those of typical businesses. Depending on the country context, these may include three separate ministries of education, health and social welfare.

As more and more women become business entrepreneurs in each of these nations. Some of the traditional roles for women will be altered. In some parts of the world, women have not historically owned businesses; however, over the last century women have gained increasing acceptance, prominence and movement into a vast assortment of enterprises (UNCTAD, 2014). In Ghana, Burkina Faso and Liberia, for primary schools in particular, it is becoming acceptable for women to have their own businesses. This appears to be particularly true since early grade education is a gendered field.

\section{IMPLICATIONS}

This section describes implications from this study for four groups of stakeholders: policymakers, institutions of higher education, the private sector and NGOs. The SDGs have only recently been created and implementation will, optimistically, be achieved by 2030. For small business owners and for women in particular, governments must ensure greater legal protections, fewer hurdles and less bureaucracy.

Goals 5 and 10 of the SDGs have targets that, if achieved, will have a significant impact on women proprietors such as those interviewed for this study. ${ }^{15}$ Goal 5: Achieve gender equality and empower women and girls, and Goal 10: Reduce inequality within and among countries, are particularly germane to the topic of this study. There are five targets from these goals that have implications for women proprietors of schools include:

- Empower and promote the social, economic and political inclusion of all, irrespective of age, sex, disability, race, ethnicity, origin, religion or economic, or other status.

- Ensure equal opportunity and reduce inequalities of outcome, including by eliminating discriminatory laws, policies, and practices and promoting appropriate legislation, policies, and action in this regard.

- Adopt policies, especially fiscal, wage, and social protection policies, and progressively achieve greater equality.

- Undertake reforms to give women equal rights to economic resources, as well as access to ownership and control over land and other forms of property, financial services, inheritance, and natural resources, in accordance with national laws.

- Adopt and strengthen sound policies and enforceable legislation for the promotion of gender equality and the empowerment of all women and girls at all levels.

Clearly, if progress on these targets is achieved, the women in this study will have greater opportunities to ensure the sustainability of their schools. The SDGs have an objective of being reached in all countries by 2030 , and there will be periodic updates of the status of the progress for each target.

\footnotetext{
${ }^{15} \mathrm{http}: / /$ www.unwomen.org/en/news/in-focus/women-and-the-sdgs.
} 
There are two implications for higher education from this study. First, working professionals need flexibility in order to continue to expand their knowledge base. Proprietors talked about the difficulty of driving to a university campus that was hours away or did not offer professional development at a time convenient for their schedules. In addition, these women not only run private schools that have issues different from government schools, but they also are running businesses; thus, it is not only schools of education, but also schools of business that need to recognize the opportunities to serve these leaders.

As governments attract the private sector in order to address the SDGs, ensuring the sustainability of programs that support entrepreneurs and leaders working in various sectors is key. The women in this study describes opportunities afforded them by the private sector, but they were short-term and thus had little impact.

Similarly, for NGOs, any loans, workshops, trainings and projects need to include plans for how and when funding for the project will cease. The development literature is replete with examples of NGOs that implement a project for 2 or 3 years and then exit without including any plans for phasing out a project or ensuring its long-term viability.

\section{CONCLUSION}

In an analysis of women leaders from various sectors in India, Malaysia, and the Philippines, Zaballero et al. (2015) found that throughout the history of these three countries, "Culture and religious observations served as impediments to gender equality for women in leadership roles... p. 263." After listening to the voices of the women in this study it appears that this is also true for women leaders in Burkina Faso, Ghana and Liberia. Gender equality has a long way to go before it is achieved in the LDCs. Duflo (2011) found a correlation between economic development and womens' empowerment, and that education is a key contributor to empowerment. Schools and universities have major roles to play in affording girls and women a high-quality education.

The women interviewed in this study have different approaches to the leadership of schools. In a groundbreaking book exploring how successful women lead schools, Grogan and Shakeshaft (2011) found that not only do women bring a spiritual dimension to their work and lead with passion, but they also demonstrate a commitment to social justice. Clearly the women in this study

\section{REFERENCES}

Arar, K. (2014). Female supervisors of Arab school education in Israel. Gend. Educ. 26, 414-431. doi:10.1080/09540253.2014.930423

Bado, A. B. (2016). Five Challenges Facing Burkina Faso's New President. Washington Post. Available at: https://www.washingtonpost.com/news/monkey-cage/wp/ 2016/01/22/four-challenges-facing-burkina-fasos-new-president-and-3reasons-for-optimism/?utm_term $=0.35$ bef5c615ce

Bush, T., and Oduro, G. (2006). New principals in Africa: preparation, induction and practice. J. Educ. Admin. 44, 359-375. doi:10.1108/09578230610676587

Charmaz, K. (2014). Constructing Grounded Theory. Thousand Oaks, CA: SAGE Publications.

Cordeiro, P., and Cunningham, W. (2012). Educational Leadership: A Bridge to Improved Practice. Boston, MA: Allyn \& Bacon. spoke about their work being spiritual. They are committed and passionate about their schools and as one proprietor stated, "This is an opportunity and a privilege for me to be useful to society ...to my nation.”

\section{ETHICS STATEMENT}

This study was carried out in accordance with the recommendations of the Institutional Review Board of the University of San Diego. All participants gave written informed consent in accordance with the Declaration of Helsinki. The protocol was approved by the Institutional Review Board.

\section{HUMAN SUBJECTS STATEMENT}

This study was carried out in accordance with the recommendations of the University of San Diego's Institutional Review Board (IRB) with written informed consent from all participants. It was approved in December 2013 by the IRB and all participants gave written informed consent in accordance with the Declaration of Helsinki.

\section{AUTHOR CONTRIBUTIONS}

PC designed the study, collected some data, completed the analysis, and wrote the first drafts. She made final approval of this version. She agrees to be accountable for all aspects of the work including ensuring that questions related to the accuracy and integrity of any part of the work are appropriately investigated and resolved. $\mathrm{CB}$ assisted with data collection and read several drafts providing feedback. She has reviewed this final version.

\section{ACKNOWLEDGMENTS}

The authors would like to thank Dorcas Adwoa Aidoo for her logistical assistance during data collection.

\section{FUNDING}

During the time of this research one of the authors was funded by the NGO to be doing other work (e.g., trainings) taking place in these nations. Neither author received any funding for research activities directly related to this study.

Cordeiro, P., and Llover, N. (2012). "Low cost private schools in Ghana: school leadership for student learning," in Proceedings of the International Council on Education for Teaching, World Congress 2012 (Cape Coast, Ghana: University of Cape Coast).

Cordeiro, P., and Spencer, J. (2015). A Study of Low-Fee Private School Leaders' Trainings in Ghana: Tema and Kumasi. A Status Report for Edify. SOLES Global Center: University of San Diego.

Creswell, J. W. (1998). Qualitative Inquiry and Research Design Choosing among Five Traditions. Thousand Oaks, CA: Sage Publications.

Day Ashley, L. C., Mcloughlin, C., Aslam, M., Engel, J., Wales, J., Rawal, S., et al. (2014). The Role and Impact of Private Schools in Developing Countries: A Rigorous Review of the Evidence. London: Department for International Development.

Dowden, R. (2008). Africa: Altered States Ordinary Minds. New York: Public Affairs. 
Duflo, E. (2011). Women Empowerment and Economic Development. Working paper 17702. Available at: https://ideas.repec.org/p/nbr/nberwo/17702.html.

Grogan, M., and Shakeshaft, C. (2011). Women and Educational Leadership. San Francisco, CA: Jossey-Bass; IDP Rising. Available at: http://www.idpfoundation.org/

Kvale, S., and Brinkman, S. (2009). Interviews: Learning the Craft of Qualitative Research Interviewing. Los Angeles: Sage.

Kwan, J. (2012). Private Schools for the Poor. Stanford Social Innovation Review. Palo Alto, CA: Stanford University.

Lumby, J., Crow, G., and Pashiardis, P. (2009). International Handbook on the Preparation and Development of School Leaders. London, UK: Routledge.

MacBeath, J., Swaffield, S., Oduro, G., and Bosu, R. (2010). "Developing leadership for learning in Ghana: opportunities and challenges," in International Congress for School Effectiveness and Improvement (Kuala Lumpur, Malaysia).

Mendonsa, E. L. (2002). West Africa: An Introduction to its History, Civilization and Contemporary Situation. Durham, NC: Carolina Academic Press.

Millennium Development Goals. (2015). New York: UNESCO. Available at: http://www.un.org/millenniumgoals/2015_MDG_Report/pdf/MDG\%202015 \%20rev\%20(July\%201).pdf.

Oduro, G., and MacBeath, J. (2003). Traditions and tensions in leadership: the Ghanaian experience. Cambridge J. Educ. 33, 441-455. doi:10.1080/03057640 32000122050

Oplatka, I. (2006). Women in educational administration within developing countries: towards a new international research agenda. J. Educ. Admin. 44, 604-624. doi:10.1108/09578230610704819

Oplatka, I. (2009). Leadership and management development in education. J. Educ. Admin. 47, 529-531. doi:10.1108/09578230910967518

Schleicher, A. (2012). Preparing Teachers and Developing School Leaders for the $21^{\text {st }}$ Century: Lessons from Around the World. Paris: OECD.

Spencer, J., Dunigan, N., Ekstrom, J., and Ouedraogo-Thomas, R. (2012). Technologies and Tools for Improving Educational Engagement in Low Cost Ghanaian Academies. Cape Coast, Ghana: International Council on Education for Teaching.
Srivastava, P. (ed.) (2013). Low-Fee Private Schooling: Aggravating Equity or Mitigating Disadvantage. Oxford, UK: Symposium Books.

Tooley, J. (2009). The Beautiful Tree: A Personal Journey into How the World's Poorest People Are Educating Themselves. Washington, DC: Cato Institute.

Tooley, J., and Dixon, P. (2007). Private school for low-income families: a census and comparative survey in East Delhi, India. Int. J. Educ. Dev. 27, 205-219. doi:10.1016/j.ijedudev.2006.08.002

UNCTAD. (2014). "A survey on women's entrepreneurship and innovation," in United Nations Conference on Trade and Development (New York; Geneva: United Nations).

Walker, A., and Dimmock, C. (2002). School Leadership and Administration: Adopting a Cultural Perspective. London: RoutledgeFarmer.

Wodon, Q. (2014). Faith-inspired schools in sub-Saharan Africa. Rev. Faith Int. Affairs 12, 1-4. doi:10.1080/15570274.2014.918754

Zaballero, A. G., Joshua-Gojer, A. E., Alsadah, Z. O., and Scamacca, L. G. (2015). "The participation of women as leaders in South and Southeast Asia," in Women and Leadership around the World, eds S. R. Madsen, F. Wambura Ngunjiri, K. A. Longman, and C. Cherrey (Charlotte, NC: International Leadership Association: Information Age Publishing), 254-268.

Zhong, W., and Ehrich, L. C. (2010). An exploration of two female principals leadership in mainland China. J.Educ. Admin. 48, 241-260. doi:10.1108/09578231011027879

Conflict of Interest Statement: The authors declare that the research was conducted in the absence of any commercial or financial relationships that could be construed as a potential conflict of interest.

Copyright $\odot 2018$ Cordeiro and Brion. This is an open-access article distributed under the terms of the Creative Commons Attribution License (CC BY). The use, distribution or reproduction in other forums is permitted, provided the original author $(s)$ or licensor are credited and that the original publication in this journal is cited, in accordance with accepted academic practice. No use, distribution or reproduction is permitted which does not comply with these terms. 